\title{
Effect of QMix 2 in 1, BioPure MTAD and 17\% Ethylenediaminetetraacetic Acid on Microhardness of Root Canal Dentin: An in vitro Study
}

\author{
${ }^{1}$ Charul Gupta, ${ }^{2}$ Gautam Singh, ${ }^{3}$ Mahesh P Singh, ${ }^{4}$ Manish Agarwal, ${ }^{5}$ Kunwar S Singh, ${ }^{6}$ Abhishek Mishra
}

\begin{abstract}
Aim: To compare the effect of QMix, a mixture of tetracycline, citric acid, and detergent (MTAD), and ethylenediaminetetracetic acid (EDTA) on the microhardness of the root canal dentin.

Materials and methods: A total of 30 single-rooted teeth were decoronated at $15 \mathrm{~mm}$ from the root apex. Root canal instrumentation using step back technique was done and the specimens were split into two halves using diamond disc. These were embedded in acrylic blocks and sent for testing by Vickers hardness test. The other half of the specimens was divided into four groups. Control group: In this, normal saline was used. Group I: MTAD was used. Group II: 17\% EDTA was used. Group IV: QMix 2 in 1 (DENTSPLY) was used. The specimens were immersed in test irrigant for 5 minutes in closed glass plates. The tested specimens were sent for Vickers hardness test under $100 \mathrm{gm}$ load for 15 seconds. The post Vickers hardness number readings were recorded and sent for statistical analysis.
\end{abstract}

Results: Data were analyzed using one-way analysis of variance and least significant difference post hoc test was applied for pairwise comparison. QMix showed significantly less reduction in microhardness than EDTA and QMix: Normal saline $>$ QMix>EDTA $>$ MTAD.

Conclusion: $Q M i x$ as a root canal irrigant is efficient as it caused least reduction of microhardness of dentin. It has antibacterial properties and is also efficient for smear layer removal.

Keywords: Acid, Detergent, Ethylenediaminetetracetic acid, Microhardness, Mixture of tetracycline, QMix.

How to cite this article: Gupta C, Singh G, Singh MP, Agarwal M, Singh KS, Mishra A. Effect of QMix 2 in 1, BioPure MTAD and $17 \%$ Ethylenediaminetetraacetic Acid on Microhardness of Root Canal Dentin: An in vitro Study. Int J Prosthodont Restor Dent 2017;7(1):17-20.

Source of support: Nil

Conflict of interest: None

\footnotetext{
${ }^{1,6}$ Postgraduate Student, ${ }^{2}$ Reader, ${ }^{3}$ Professor and Head ${ }^{4}$ Professor, ${ }^{5}$ Assistant Professor

${ }^{1-4,6}$ Department of Conservative Dentistry and Endodontics People's College of Dental Sciences and Research Centre Bhopal, Madhya Pradesh, India

${ }^{5}$ Department of Conservative Dentistrty and Endodontics, Santosh Dental College and Hospital, Ghaziabad, Uttar Pradesh, India

Corresponding Author: Charul Gupta, Postgraduate Student Department of Conservative Dentistry and Endodontics, People's College of Dental Sciences and Research Centre, Bhopal Madhya Pradesh, India, Phone: +918602033502, e-mail: dentistcharul28@gmail.com
}

\section{INTRODUCTION}

An irrigant may have the ability to remove the smear layer without any erosion to the dentin and also to remove the microorganisms at the same time so that reinfection is prevented. ${ }^{1}$

The irrigants used in routine dental practice are normal saline, sodium hypochloride $(\mathrm{NaOCl})$, ethylenediaminetetraacetic acid (EDTA), and chlorhexidine (CHX). ${ }^{2}$ These are reported to alter the chemical composition of dentin that can cause changes in the microhardness of dentin. The ratio of calcium to phosphorous changes with the use of various irrigants. ${ }^{1}$ Determination of microhardness can provide knowledge about the mineral loss or gain in the dentin as it affects the sealer penetration and hence, the seal of the root canals will be affected. ${ }^{1}$

Sodium hypochlorite with the concentration ranging from 1 to $5.25 \%$ has been used as a root canal irrigant for a long time. It is an organic solvent for vital, necrotic, fixed tissues; however, it has been proven that it is not effective in removing the smear layer. ${ }^{3}$

Ethylenediaminetetraacetic acid, a chelating agent, is used effectively with $\mathrm{NaOCl}$ to remove the smear layer. The disodium salt for EDTA (17\%) and neutral $\mathrm{pH}$ is commonly used. This irrigant alone is not effective for the removal of organic tissues. ${ }^{4}$

Chlorhexidine is a broad spectrum antimicrobial agent but should be used as a final irrigant as by itself it does not show any tissue-dissolving properties similar to $\mathrm{NaOCl}$ or the chelating action shown by EDTA. ${ }^{5}$

These various different irrigants were advocated to be used separately to achieve maximum effect, but this leaves the clinician using a lot of time and resources on irrigation protocol alone. So a new irrigant was sought after, which has most of the favorable properties and effect in the root canal system together for better patient management and effective cleaning and shaping of the root canal system. ${ }^{6}$

BioPure mixture of tetracycline, citric acid, and detergent (MTAD), is a mixture of doxycycline, citric acid, and polysorbate 80 also referred to as Tween 80 . It is being marketed by DENTSPLY / Tulsa Dental as an antibacterial root canal cleanser. ${ }^{2}$

Another new material used in the study is QMix 2 in 1 (DENTSPLY Tulsa Dental, Tulsa, OK, USA), which 
is an antimicrobial agent that contains EDTA, CHX, and detergent. Due to the chemical design in QMix 2 in 1, no white precipitate is formed; hence, it can be used easily. ${ }^{1}$

The aim of this study is to determine the microhardness of root dentin after irrigation with different irrigating solutions using Vickers hardness test.

\section{MATERIALS AND METHODS}

\section{Specimen Preparation}

Thirty freshly (Fig. 1) extracted teeth were selected and stored in a sterile saline solution at room temperature. Teeth were radiographed to confirm the presence of single canal.

Teeth were decoronated (Fig. 2) at $15 \mathrm{~mm}$ from the apex using a digital vernier caliper. ${ }^{2}$

The working length was established by inserting a \#15 k file into the root canal until its tip was visualized at the apex and then subtracting $1 \mathrm{~mm}$ from this measurement. ${ }^{1}$ The root canal was prepared till master apical size

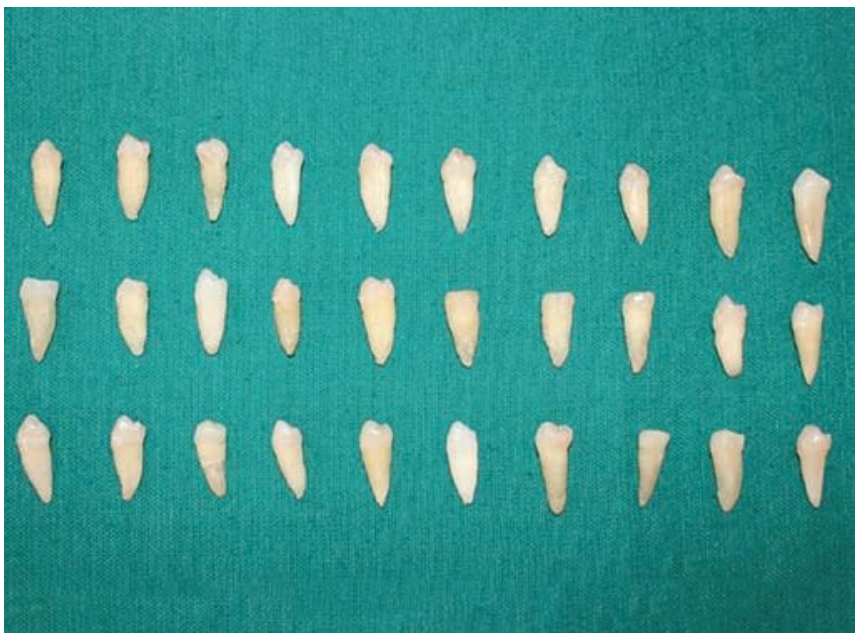

Fig. 1: Thirty freshly extracted teeth were selected as specimens

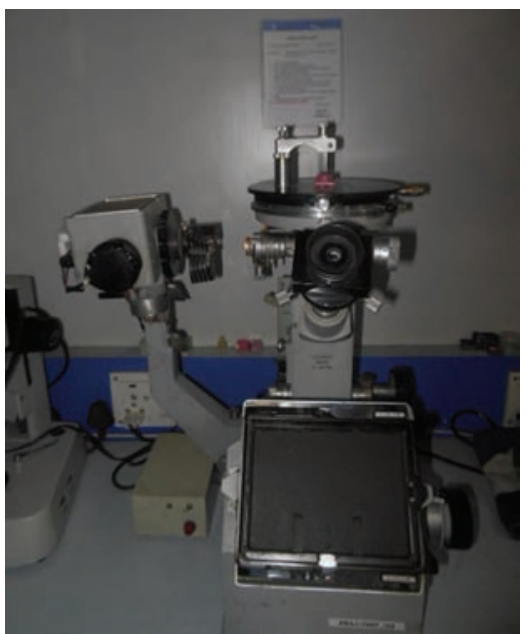

Fig. 3: Vickers hardness test
$50 \mathrm{~K}$ file using step back technique and recapitulation using distilled water as an intracanal irrigant during instrumentation.

Root specimens were split with a diamond disk into two segments giving 60 halves. Each prepared root was horizontally embedded in an acrylic block. Each root half was labeled accordingly.

\section{Microhardness Evaluation}

Microhardness was measured for each sample using Vickers hardness test (Fig. 3). Each measurement was carried out using $100 \mathrm{gm}$ load for 15 seconds. The hardness value for each sample was recorded. ${ }^{2}$

\section{Evaluation of Microhardness for Tested Irrigants}

For testing the irrigants for microhardness, the specimens were divided into four groups $(n=15)$ :

Control group specimens were immersed in normal saline (Fig. 4).

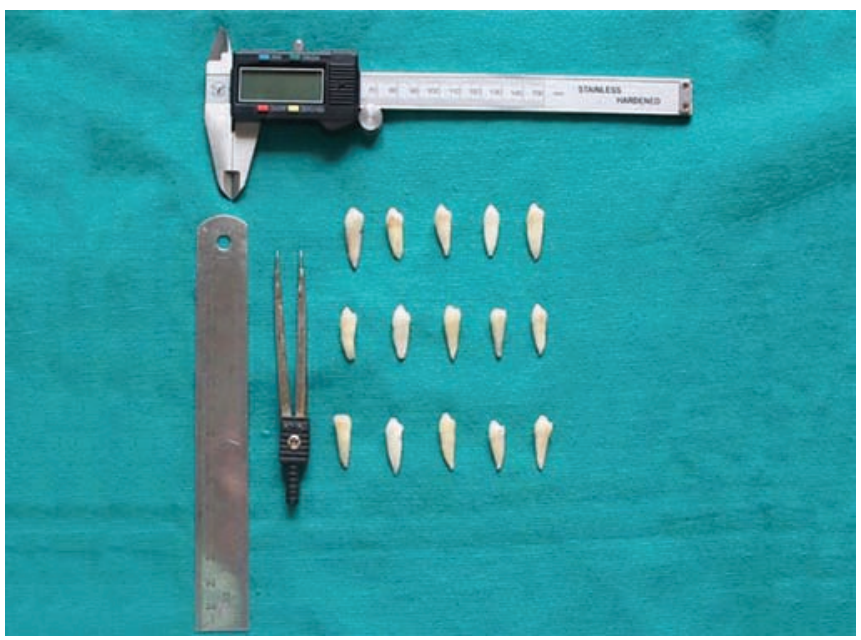

Fig. 2: Teeth were decoronated at $15 \mathrm{~mm}$ from the apex

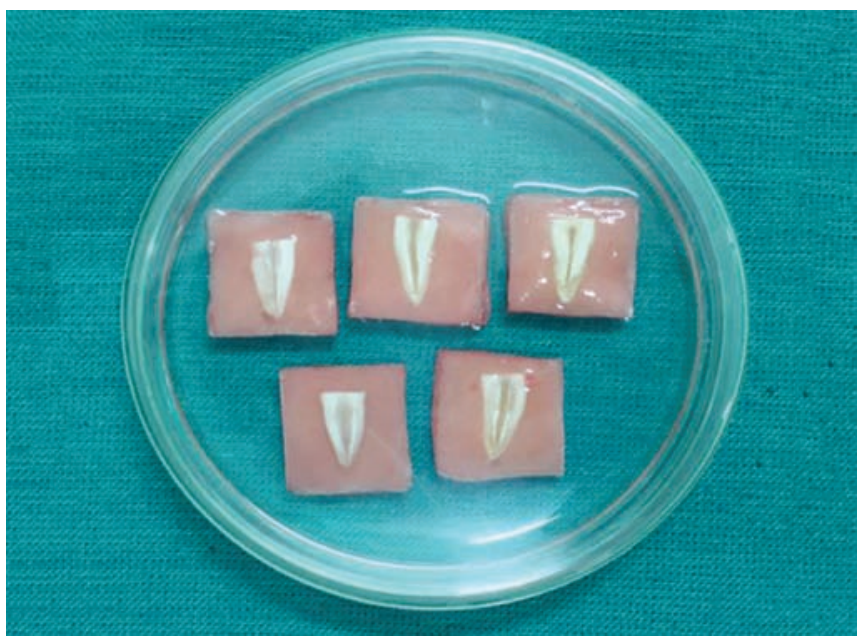

Fig. 4: Specimens immersed in irrigants in closed glass plate 


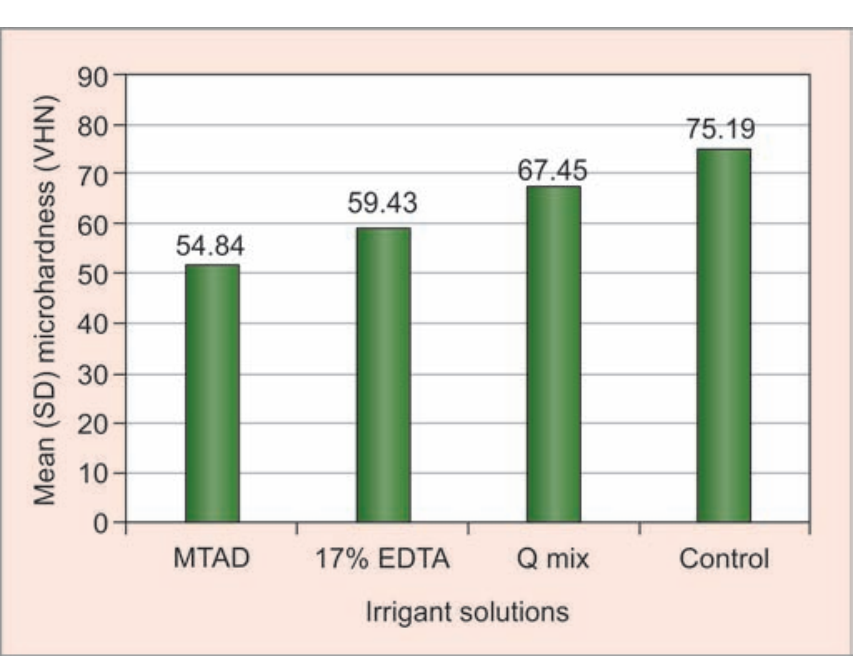

Graph 1: Comparison of microhardness of all groups

Group I specimens were immersed in Biopure MTAD (Dentsply Tulsa Dental, OK, USA).

Group II specimens were immersed in 17\% EDTA (Prevest DenPro ${ }^{\mathrm{TM}}$ ).

Group III specimens were immersed in QMix 2 in 1 (Dentsply Tulsa, OK).

The excess moisture was eliminated with sterile paper points kept over the horizontally cut root canal to prevent dilution of the experimental irrigants before sample immersion.

The root sections were mounted in acrylic blocks and were immersed in the test irrigant solution for 5 minutes each in closed glass plates at room temperature.

The specimens were then flushed with distilled water and dried with sterile paper points.

The microhardness was measured for each sample at the exposed canal dentin surface as posttreatment Vickers hardness number.

The microhardness was recorded for the same and results were sent for statistical analysis.

\section{Statistical Analysis}

The data were collected and tabulated for statistical analysis and a descriptive analysis was done using one-way analysis of variance (ANOVA). After one-way ANOVA, Fisher's least significant difference test, post hoc test was applied for pairwise comparison (Graphs 1 and 2).

\section{RESULTS}

One-way ANOVA showed significant difference between different irrigants $(\mathrm{F}=2229.717, \mathrm{p}<0.01)$.

All irrigating solutions showed decrease in the microhardness except saline. The results concluded that the control group had significantly higher microhardness than other irrigating solutions. In comparison, the microhardness

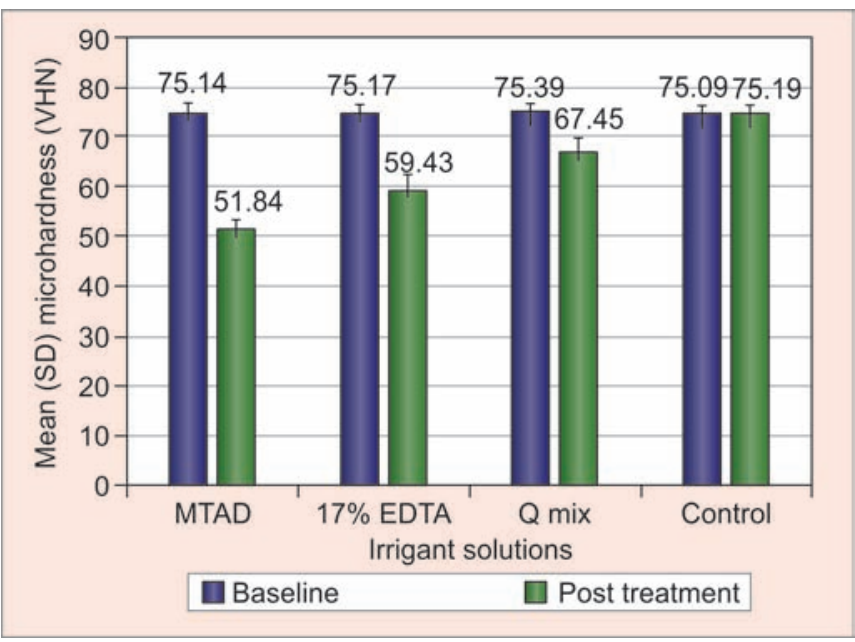

Graph 2: Mean microhardness before and after treatment of specimens

of QMix was found to be significantly higher than $17 \%$ EDTA and MTAD. The 17\% EDTA showed significantly higher microhardness than MTAD.

NS $>$ QMIX $>$ EDTA $>$ MTAD.

\section{DISCUSSION}

The microhardness of dentin depends on the physical properties of the solution ( $\mathrm{pH}$ and concentration) and structure of dentin (tubular density, location, age). The number and diameter of dentinal tubules also play an important role in the effectiveness of irrigants. ${ }^{4}$

The primary factors that govern the action of an irrigant are contact time and concentration. The optimum time the irrigant should be in contact with the root canal. Ulusoy and Görqül ${ }^{7}$ and used the irrigants for 5 minutes as duration is important in clinical practice. Accordingly, in this study, all irrigating solutions were used for a contact time of 5 minutes. Distilled water was used as an irrigant initially because it has no effect on dentin surface.

Knoop indenter microhardness test and the Vickers indenter method have been used to measure the hardness of dentin. However, Vickers microhardness test was preferred in this study because of the method's suitability and practicality of Vickers test for evaluating surface changes of deeper dental hard tissues. Microhardness measurement was done in three points, coronal, middle, and apical third of the root canal dentin. ${ }^{2}$

A possible limitation of the study can be that the experiments were performed at room temperature and not at body temperature. Another can be the volume of the irrigant used; however, standardization of the study allowed for comparable results.

The chelating agent EDTA used in the study is used to remove the smear layer from the root canal because the components of this loosely bound structure are very small particles with a large surface mass ratio that 
makes them very soluble in acids. ${ }^{8,9}$ Sousa and Silva, ${ }^{10}$ have shown that EDTA facilitates chelation of inorganic portion of dentin and $\mathrm{NaOCl}$ promotes dissolution of its organic portion. ${ }^{11}$

The decreased microhardness of dentin using MTAD is due to its chelating components. ${ }^{5}$ It has $4.25 \%$ citric acid, which is capable of solving the mineral contents of dentin. De-Deus et al ${ }^{12}$ stated that although citric acid has the same concentration as EDTA, the $\mathrm{pH}$ is different. The more the acidic $\mathrm{pH}$, the more the removal of calcium ions from dentin.

QMix is composed of EDTA, CHX, and a surfactant. The addition of surfactant to the chelating agent leads to reduction in dentin microhardness as it reduces the surface tension ${ }^{13}$ and hence, increases the ability of the chelator to penetrate the dentin easily, but the results of the present study showed that QMix causes the least reduction in microhardness of the root canal dentin. This is in accordance with a study done by Kara Tuncer et al. ${ }^{1}$

The present study revealed that all irrigation solutions decreased dentin microhardness with the exception of saline. QMix ${ }^{\mathrm{TM}}$ has been proven to have good properties, such as biocompatibility, antibacterial action, smear layer removal, and less impact on dentin microstructure of root canal dentin (Tables 1 and 2).

\section{CONCLUSION}

The results of this study showed that with conventional irrigation regimen, the dentin microhardness was reduced significantly. QMix 2 in 1 with an application of 5 minutes caused least reduction of microhardness followed by EDTA and MTAD, probably as it compromises a combination of various substances, including surface active agent. Within the limitations of this in vitro study, it can be concluded that the use of $\mathrm{QMix}^{\mathrm{TM}}$ will not hamper the root canal microhardness significantly when compared with the EDTA and MTAD.

\section{CLINICAL SIGNIFICANCE}

Within the limitations of the study, it can be revealed that QMix 2 in 1(Dentsply) as an irrigant has significantly higher properties than the other irrigants, such as EDTA and MTAD, as it has reduced effect on the microhardness of the root canal dentin as well as antibacterial properties and can remove smear layer easily.

\section{REFERENCES}

1. Kara Tuncer A, Tuncer S, Siso SH. Effect of Qmix irrigant on microhardness of dentine. Aust Dent J 2015 Jun;60(2):163-168.

2. Kandil HE, Labib AH, Alhadainy HA. Effect of different irrigant solutions on microhardness and smear layer removal of root canal dentin. Tanta Dent J 2014 Apr;11(1):1-11.

3. Zehnder M. Root canal irrigants. J Endod 2006 May;32(5): 389-398.

4. Zhang K, Kim YK, Cadenaro M, Bryan TE, Sidow SJ, Loushine RJ, Ling JQ, Pashley DH, Tay FR. Effects of different exposure time and concentration of sodium hypochlorite/ ethylenediaminetetraacetic acid on the structural integrity of mineralized dentine. J Endod 2010 Jan;36(1):105-109.

5. Kalluru RS, Kumar ND, Ahmed S, Sathish ES, Jayprakash T, Garlapati R, Sowmy B, Reddy KN. Comparative evaluation of the effect of EDTA, EDTAC, NaOCl, MTAD on microhardness of human dentine - an in-vitro study. J Clin Diagn Res 2014 Apr;8(4):ZC39-ZC41.

6. Kamakshi G, Suvarna N, Shetty HK, Khed J. Relation between calcium loss and its effect on microhardness of root canal dentin following treatment with $17 \%$ ethylene diamine tetraacetic acid (EDTA) at different time intervals: an ex-vivo study. J Int Med Dent 2014;1(2):75-85.

7. Ulusoy ÖÍ, Görqül G. Effects of different irrigation solutions on root dentine microhardness, smear layer removal and erosion. Aust Endod J 2013 Aug;39(2):66-72.

8. Uzunoglu E, Tuker SA, Ozcelik B. The effectiveness of various chelates alone or in combination with sodium hypochlorite in the removal of calcium hydroxide from root canals. Saudi Endod J 2015 Sep-Dec;5(3):161-165.

9. Dineshkumar MK, Vinothkumar TS, Arathi G, Shanthisree P, Kandaswamy D. Effect of ethylene diamine tetra acetic acid, MTADTM and HEBP as root canal irrigant. J Conserv Dent 2012 Apr-Jun;15(2):170-173.

10. Sousa SMG, Silva TL. Demineralization effect of EDTA, EGTA, CDTA and citric acid on root dentin: a comparative study. Braz Oral Res 2005 Jul-Sep;19(3):188-192.

11. Cruz-Filho AM, Sousa-Neto MD, Savioli RN, Silva RG, Vansan LP, Pécora JD. Effect of chelating solutions on the microhardness of root canal lumen dentine. J Endod 2011 Mar;37(3):358-362.

12. De-Deus G, Paciornik S, Mauricio MH. Evaluation of the effect of EDTA, EDTAC and citric acid on the microhardness of dentine. Int Endod J 2006 May;39(5):401-407.

13. Akcay I, Sen BH. The effect of surfactant addition to EDTA on microhardness of root dentine. J Endod 2012 May;38(5):704-707. 